\section{EL CINE DE PILAR MIRÓ. HOMENAJE Y PUENTE HACIA LA LITERATURA}

\author{
Concepción Fernández Soto \\ IES "Fuente Nueva", El Ejido (Almería)
}

\section{Francisco Checa y OImos}

Universidad de Almería

\begin{abstract}
There is absolutely no doubt about the fact that literature -including both novel and theatre- has provided the cinema with great stories throughout the last one hundred and twenty years. And why is a literary text chosen to be adapted to the cinema? Among others, the main reasons are the necessity to tell well-constructed stories which will undoubtedly be successful, the access to historical knowledge or the recreation of myths and emblematic literary works. As far as Pilar Miró is concerned, the most important thing about her adaptations is that the original perception, reading and personal vision of the literary work remain, though always through the dialogue among creators. This research work studies in detail the five films adapted from literary works that Pilar Miró directed, five works that resulted from her personal admiration for these literary works' quality and suggesting power.
\end{abstract}

KEY WORDS: Literature and cinema; film adaptations; Pilar Miró; La Petición; Werther; Beltenebros; Tu nombre envenena mis sueños; El perro del hortelano.

"Yo he hecho cine porque he leído, o he leído porque he hecho cine. No lo sé"

(Antonio Saura).

Más allá del debate acerca de la (im)posibilidad de trasvasar ideas, argumentos, técnicas y sensaciones de la novela a la gran pantalla, y sobre la jerarquía de prestigio entre ambas artes, es incuestionable que la literatura ha proporcionado un gran caudal de buenas historias al cine a lo largo de sus casi ciento veinte años de vida, y si en ese camino inicial el teatro suministró un buen número de ellas, a partir de la segunda década del siglo veinte la novela se consolidará como la forma literaria más apta para ser trasladada al celuloide.

Pero al abordar la relación literatura/cine lo habitual es referirse a la influencia temática, a la adaptación de textos literarios al cine, en un proceso tan antiguo como el mismo cinematógrafo. ¿Y por qué se elige un texto literario o teatral

\section{PILAR MIRÓ'S FILMS. A TRIBUTE AND LINK TO LITERATURE}

RESUMEN: Es incuestionable que la literatura -tanto la novela como el teatro- ha proporcionado grandes historias para el cine a lo largo de sus casi ciento veinte años de existencia. ¿Y por qué se elige un texto literario para ser adaptado? Entre otras razones por la necesidad de contar con historias bien trazadas, por la garantía del éxito comercial, el acceso al conocimiento histórico o por la recreación de mitos y obras emblemáticas.

En el caso de la directora Pilar Miró lo importante de sus adaptaciones es que finalmente prevalece su percepción, su lectura, su visión personal de la obra original, pero siempre a través del diálogo entre creadores. El texto de este artículo estudia las cinco películas que $\mathrm{Pi}$ lar Miró dirigió como adaptaciones de obras literarias, cinco trabajos que vinieron como resultado de un deslumbramiento personal ante la calidad y el poder de sugerencia de esos textos literarios.

PALABRAS CLAVE: Literatura y cine; adaptaciones cinematográficas; Pilar Miró; La petición; Werther; Beltenebros; Tu nombre envenena mis sueños; El perro del hortelano.

para ser adaptado? Según Sánchez Noriega $(2000,47)$ la adaptación es "el proceso por el que un relato, la narración de una historia, expresado en forma de texto literario, deviene, mediante sucesivas transformaciones en la estructura..., en el contenido narrativo y en la puesta en imágenes... en otro relato muy similar expresado en forma de texto fílmico". Y añade que las razones por las que se adaptan obras literarias al cine son entre otras posibles la necesidad de historias, la garantía de éxito comercial, el acceso al conocimiento histórico, la recreación de mitos y obras emblemáticas, el prestigio artístico y cultural y la labor divulgadora $(2000,50-52)$.

Vemos que las razones son múltiples, y lo negativo es que a menudo se sitúan al margen de una lógica que nos haga pensar en una demanda por parte del público o en la virtualidad cinematográfica del original. Pero no es el caso de la directora que nos ocupa. Analicemos sus razones. 


\section{LA ADAPTACIÓN CINEMATOGRÁFICA: el CASO de PILAR Miró}

Entendemos la adaptación cinematográfica como una transformación de la obra original, pero tratando siempre de preservar su esencialidad. Así todas las modificaciones, transformaciones y ajustes que se realicen no deben impedir que se siga reconociendo el material originario literario, y van a tener que ver con criterios estéticos relacionados con la sensibilidad del realizador, con su concepto del ritmo y su estilo personal.

En el caso de las adaptaciones de Pilar Miró, estos cambios afectan principalmente a la presentación de los personajes, a su configuración, a la estructura (sobre todo en la utilización del tiempo, con cierto exceso en los flash-back utilizados), al tratamiento de la anécdota (se añaden o suprimen ciertos episodios o fragmentos narrativos), o a cambios en las coordenadas de tiempo y espacio y a la atmósfera. Y lo que creemos más importante es que siempre prevalece su percepción, su lectura, su visión personal de la obra original. Esa obra original tiene una calidad probada, algunas veces con el añadido de ser éxitos editoriales (caso de las novelas de Muñoz Molina y Joaquín Leguina), lo que las convierte en una plataforma de trabajo más estable que un guión original; pero en otros casos la apuesta es más arriesgada, ya que es un material base más inexplorado (como en el caso del teatro de Lope de Vega).

En este proceso asistimos a un:

[verdadero] diálogo entre dos creadores. El realizador se reivindica como autor, que busca imprimir las huellas de su creatividad, firmar con su nombre la obra que construye, pero sin borrar ni la creación literaria preexistente ni el nombre del escritor. La película se convierte en una variante, más o menos trabajada, del libro, una obra hermana de la obra original, que afirma a la vez su propia originalidad y la irrefutable identidad que la liga a su hermana mayor (Jaime, 2000, 110).

El interés de su trabajo cinematográfico radica, pues, en ese tránsito, en ese doble ejercicio entre lo que se capta y lo que se devuelve, en esa labor de puente entre el autor del libro y el espectador de la película. Decidir lo que se conserva, lo que se suprime, lo que se añade, determinar el género del relato filmico, en qué aspectos se va a incidir más: en los personajes, en el ambiente, en la atmósfera, en el ritmo y valor dramático de la acción, en el fluir del tiempo, etc., es una tarea que Pilar Miró asume con minuciosidad de cirujano, proceso que se torna paralelo o similar a la escritura de un guión original, con la diferencia, en su caso, de que parte de unos materiales literarios, narrativos y teatrales que la han deslumbrado previamente, que la han impulsado emocionalmente a trazar esos puentes hacia el espacio filmico. Asi dirá: "cuando trabajo necesito sentirme cerca de aquello que otro ha contado, cuando y como sea, para poder a mi vez traducirlo y ser mediadora" (El País, 03/05/1997). Y esa labor de acercamiento se concretó finalmente en cinco adaptaciones literarias, quedándose en el camino muchos otros proyectos, como ya iremos señalando en su momento.

Tras su primera adaptación de un texto literario de época, La petición (1976), hasta diez años después no llegaría Werther, un proyecto que vino de la mano de una obra literaria que le habia fascinado desde siempre, y que por un personal impulso romántico se trasladó a la pantalla. Su tercera adaptación, Beltenebros (1991), aparece en forma de encargo de la productora de Andrés Vicente Gómez y se convierte en una exquisita y cuidadosa traslación del original de Muñoz Molina. Tu nombre envenena mis sueños (1996) constituiria un encuentro sentimental con el Madrid de la posguerra y una coincidencia generacional con la novela de Joaquín Leguina. Con El perro del hortelano (1996), Pilar Miró cierra su deuda cinematográfica con el teatro, género al que ella le había prestado una especial atención desde sus primeras adaptaciones para la televisión y sus montajes en vivo.

\section{SUS INICIOS PROFESIONALES EN TELEVISIÓN}

La trayectoria artística de Pilar Miró se desarrolla en medio de circunstancias sociopolíticas inherentes a un presente histórico dependiente de acontecimientos pasados sin resolver, confrontando al espectador con su inconsciente colectivo y su contexto personal, en un cine "bajo la paradoja", en palabras de Monterde (1993).

Esto va a ser así desde su primera película: cabe señalar que a partir del estreno en 1976 de La Petición, y hasta su muerte el 19 de octubre de 1997, Pilar Miró dirigió ocho películas más: El crimen de Cuenca (1979), Gary Cooper que estás en los cielos (1980), Hablamos esta noche (1982), 
Wether (1986), Beltenebros (1991), El pájaro de la felicidad (1993), Tu nombre envenena mis sueños (1996) y la última, El perro del hortelano (1996). Con la tenacidad que la caracterizaba, seguro que Pilar Miró hubiese dirigido más películas, si la muerte no se la hubiera llevado tan pronto. También la persistencia es lo que la definía en su personalidad pública. Ella permanecía firme y creyendo en sus proyectos audiovisuales, y en sus propuestas de organización y creación que conllevaba la gestión de los cargos públicos de la Dirección General de Cinematografía y de la Dirección General de RTVE, que ocupó durante los años de Gobierno Socialista en 1983-1985 y 1986-1989, respectivamente.

Pero volviendo a sus inicios podemos señalar cómo Pilar Miró Romero (1940) era una niña introvertida que buscaba mundos ficticios para escapar de una realidad familiar que le era hostil en esa larga posguerra española; su infancia en Madrid estuvo condicionada por la seca figura de su padre, un militar represaliado al finalizar la guerra civil, y por una madre, oscura y poco tierna, que pareció ejercer poca influencia sobre su personalidad. Pero muy pronto encontraría refugio en la literatura y en el cine: así se revelaría como una lectora voraz (fascinación por los grandes realistas españoles y europeos) y una asidua a la butaca de cine (lo cuenta con detalle en Massanés, 1978, 121-165).

Estudió Derecho y Periodismo, sin terminar ninguna carrera, y se licenció en Guión en la Escuela Oficial de Cinematografía, donde más tarde será profesora de montaje y de guión. En 1960 comenzó a trabajar en televisión como auxiliar de redacción. Tres años más tarde realizará su primer programa de televisión, "Revista para la mujer" y poco a poco se irá forjando profesionalmente en la realización de espacios para la TV: cantera de argumentos literarios y una escuela inmejorable para aprender el oficio.

Su debut en la realización de dramáticos se produjo en 1966 para el espacio "Novela", bajo el título Lilí (una adaptación de Fernando García de la Vega a partir del relato de Paul Gallicet). Había que Ilenar una vacía parrilla televisiva y el esquema del folletín decimonónico era el ideal, con autores canonizados por la tradición literaria, y autores asimilados por el régimen político imperante. A lo largo de dos años ese espacio, "Novela", fue el campo de batalla de la realizadora y sirvió para acercar al público de televisión relatos, novelas y dramas de escritores, como Concha Alos, Manuel Tamayo, Gonzalo Delgrás, José María Pemán, Leopoldo Alas "Clarín", Ignacio Aldecoa, incluso con guiones propios. En resumen, Pilar Miró buceaba continuamente en la literatura, buscando sugerencias para sus trabajos televisivos, y en ese rastreo aparecian autores tolerados y unos pocos "contestados". Sin abandonar las "Novelas", el siguiente paso importante vendria de la mano de su primer Estudio 1, en 1968, sobre la obra de Miguel Mihura, Sublime decisión. Y en ese mismo año también se fija en José Martín Recuerda, un dramaturgo "contestado" y poco afecto al régimen, adaptando su obra Como las secas cañas del camino. Así recuerda la propia Pilar Miró esa época de tanteos profesionales:

Dirigir una obra de un autor "contestado" como Martín Recuerda era casi una heroicidad que recuerdo con cariño. Creo que en el fondo nunca hice nada que no quisiera hacer, pero tampoco pude hacer nunca lo que quería. Jamás me preguntó nadie: ¿Qué quieres hacer? A mí me interesaba mucho adaptar, por ejemplo, un Shakespeare, Romeo y Julieta, o en novela Mujercitas. Ni siquiera los éxitos me daban opción a elegir. Pero a mi lo que más me interesaba era trabajar, experimentar, jugar con la música, los decorados y los tiempos, incorporar actores nuevos... Y pensar constantemente en la posibilidad de hacer cine. No había manera. El gran obstáculo era, precisamente, el hecho de ser realizadora de televisión. Al contrario de lo que ocurría en el cine americano, por ejemplo, aquí constituía una dificultad insuperable. Los productores decian: "Pilar Miró es de televisión". Y no habia nada que hacer (Pérez, 1992, 62-63).

Siguieron en la década de los 70 una variada serie de encargos para Pilar Miró, que debió abordar casi simultáneamente, y entre los que destaca su exitoso trabajo para el espacio "Novela" La pequeña Dorrit (de Dickens) ynuevas y voluminosas versiones de textos clásicos de la literatura, por los que desde niña se sentía atraída como lectora: La feria de las vanidades, de W. Thackeray, Humillados y ofendidos, de Dovstoievski, De la misma sangre y Danza Macabra, de Strindberg, El escarabajo de oro, de Allan Poe, y, sobre todo, Aventura de un estudiante alemán, un texto de W. Irving y adaptación de Juan Tébar, que posteriormente sería la simiente de su Werther cinematográfico. En 1974 consigue grabar su primera producción televisiva en soporte de celuloide, Cuentos de Giovanni Boccaccio, para el espacio cultural "Los libros", luego rodaría Ópera

ARBOR CLXXXVI 741 enero-febrero [2010] 79-88 ISSN: 0210-1963 
en Marineda, basada en un relato de Emilia Pardo Bazán (véase González Herrán, 2007)' y para el espacio "Cuentos y leyendas", una adaptación de Los tres maridos burlados, de Tirso de Molina (a la sazón su primer acercamiento al teatro clásico, que tan buenos resultados le darían posteriormente en El perro del hortelano).

Esta etapa en TV sería una gran escuela de aprendizaje -ahí está el origen de sus posteriores trabajos cinematográficos-, pues le proporcionó la destreza y el oficio necesarios para extraer de cualquier texto un relato especificamente audiovisual, fiel y capaz de explorar sus diversas posibilidades expresivas, y también le daría el conocimiento necesario para abordar el salto a la gran pantalla (toda su producción en TV puede verse en Santamarina, 1998). Con la llegada de la democracia, Pilar Miró buscaba reencontrarse con una historia, una cultura y una tradición literaria hasta entonces confiscada, para lo cual recuperó autores vetados hasta entonces -los primeros pasos ya los había dado en TV- y comenzó a frecuentar la libertad de expresión y la literatura de calidad, en un complicado camino hacia sus primeros largometrajes².

\section{LA PETICIÓN, ADAPTACIÓN DE UN RELATO DE ÉPOCA}

Después de 15 años de trabajo en TV, Pilar Miró encontraría la oportunidad de acercarse a la gran pantalla. Juan Tébar había encontrado en una antología de cuentos el relato de Émile Zola, "Por una noche de amor", y había trabajado con Pilar Miró su transformación en un guión televisivo que luego abandonarian, pues resultaba demasiado atrevido en ese formato. En 1976 volvería a ese texto y firmaría el contrato que la convertiría al fin en directora de cine. La película se tituló La petición y en ella destacan dos aspectos: de un lado, su carácter de adaptación literaria de un relato decimonónico, que lo asemeja a los anteriores trabajos de la autora en TV; por otro, el hecho de que la primera obra cinematográfica de una de las escasas mujeres que accedieron a la dirección -salvo Ana Mariscal y Josefina Molina-, presente como figura central a un personaje femenino, que en términos convencionales podría considerarse "negativo", pues se escapa al modelo prototípico de "ángel del hogar" al que los espectadores estaban acostumbrados.
Así en La petición nace el primer personaje femenino, tan habitual en toda la filmografía de Miró: fuerte, compleja e independiente, el prototipo de mujer que reencontraremos de nuevo en sus posteriores trabajos, ya tejida con muchos hilos de su biografía. En la película, Teresa -personaje típicamente marcado por el determinismo zoliano- se educa como hija única de un rico hacendado y desde pequeña demuestra su tendencia a esclavizar a los inferiores: a Miguel, el hijo del ama de llaves, con el que jugaba de pequeña sometiéndolo siempre a su voluntad, y a un vecino que es mudo, y al que hace prometer que hará todo lo que ella le pida a cambio de su favores. Teresa va a prometerse en matrimonio con Mauricio y justo antes del baile de la petición de mano, en uno de sus encuentros con Miguel, éste fallece, accidentalmente, en la cama de Teresa. Ella llama al vecino para que le ayude a deshacerse del cadáver, al final conseguirá liberarse de ambos, antes de volver al baile e iniciar inmutable un vals con su prometido.

El principal reto para los guionistas era alargar el breve relato del original de Zola hasta Ilegar a 90 minutos. Para ello desarrollaron más el personaje de Teresa, en detrimento del mudo, que en la novela no lo es y que en la película pierde su carácter referencial, ayudando a trenzar más la trama argumental, porque es manejado por la protagonista para la consecución de sus fines. La transformación del personaje de Teresa en protagonista absoluta despertó un interés añadido a la película y animó la discusión en torno a uno de los tópicos que más irritaba siempre a la autora: la adscripción de cualquier asunto o conflicto a las esferas de "lo masculino" y "lo femenino" como categorías determinantes.

La petición alcanzó un razonable éxito de crítica ${ }^{3}$ y pareció abrir definitivamente a Pilar Miró las puertas de la dirección, aunque tendría que esperar casi tres años y guardar en el cajón varios guiones antes de poder afrontar efectivamente un nuevo largometraje, Gary Cooper que estás en los cielos que se estrenaría finalmente el 24 de noviembre de $1980^{4}$. Se quedaron en el cajón los homenajes a dos autoras que, aunque representantes de diferentes épocas literarias, le interesaban mucho a Pilar Miró: Emilia Pardo Bazán y Los pazos de Ulloa, -más tarde haría real este proyecto Gonzalo Suárez- y, en 1977, Carmen Martín Gaite, a través del realismo existencial de Fragmentos de interior. 
Al tiempo que se sucedian los proyectos de TV, en 1978 tuvo lugar en Madrid el primer Congreso Democrático del Cine Español, en el que esta directora, ya afiliada al PSOE, participó activamente, integrando la Comisión Permanente. Irrumpía así, de manera pública en el campo de la organización y el desarrollo de las estructuras del cine y la TV en España, y también buscaba con ahínco la vuelta a la dirección de largometrajes. Miró lo hizo con El crimen de Cuenca, película lista para el estreno en 1979, con guión de Lola Salvador y la propia Miró, y que le valió un largo proceso militar, por lo que no pudo exhibirse hasta 1981, convirtiéndose en la película más taquillera del año.

\section{WERTHER, MORIR DE AMOR}

Tras la adaptación de La petición y la investigación histórica de El crimen de Cuenca, Pilar Miró iría consolidando un universo fílmico rico en referencias literarias y que tomaría su plena expresión en Werther (1986). No obstante, con anterioridad ya había indagado en su propio universo personal -con Gary Cooper que estás en los cielos (1980)- y, dos años más tarde, con Hablamos esta noche (1982) pretendió hacer un retrato crítico de los valores dominantes de una sociedad que a punto estaba de llevar al poder a un gobierno socialista. Esta película también cerraría una etapa en su filmografía, coincidiendo con los nuevos aires políticos llegados a nuestro país -si bien aún no cerraba las páginas del pasado-. Miró intervino en la campaña electoral del PSOE y tras la victoria, a finales de 1982 le llegó el nombramiento de Directora General de Cinematografía y las Artes Audiovisuales, que mantuvo hasta diciembre de 1985.

Después de renunciar a la Dirección General -quería volver a hacer cine- en Werther (1986) Pilar Miró se reencuentra e intensifica su relación con la materia prima literaria. Esta película era la materialización de un proyecto cinematográfico que tenía en mente desde largo tiempo: una adaptación del Die Leiden des jungen Werthers, de Goethe, publicada en 1774. Miró conocía bien la obra literaria y en la adaptación le fue pasando el tamiz de la ópera de Jules Massenet, que había hecho para televisión años antes. Ambas, novela y ópera, siempre le habían llamado la atención a Miró por razones temperamentales, atraída por un tema que más bien era un desafío a la moda cinematográfica del momento:

Tengo la sensación de que ahora necesito hacer una película apasionada y de sentimientos, esos sentimientos que puse en tela de juicio en Hablamos esta noche y que, sin embargo, son inalterables e intemporales. $Y$ es que a mi siempre me ha fascinado Werther, siempre: porque es un hombre revolucionario y absolutamente radical que, sin embargo, es capaz de vivir grandes pasiones (en declaraciones a Rosa Montero en El País, 16/09/2008).

Ella misma situaba en 1970 la fecha en la que pensó por primera vez adaptar la novela del romántico alemán. Estuvo en varias ocasiones a punto de iniciarlo, siempre respetando la época original en la que transcurre la novela; pero fue en 1986 cuando, tras el deseo de volver a dirigir y debido a razones presupuestarias decidió trasladar a la época actual la novela Las penas del joven Werther, algo de lo que con claridad se arrepentiría con posterioridad: "Sigo pensando que esta película fue un error. Nunca debí renunciar a ambientar Werther en su época" (Angulo, 1998, 24). El propósito inicial era hacer una adaptación fiel a Goethe, impulsada por una urgente necesidad de reflexionar sobre el individuo y las relaciones humanas; pero terminó siendo una historia basada en la "libre interpretación de los personajes de Goethe", situados en la época actual: los bosques alemanes de finales del siglo XVIII se convierten en los grises y verdes de una Cantabria de dos siglos después, ahora bien, sin atemperar los componentes románticos del texto original.

En esta película un joven profesor romántico y melancólico imparte sus clases de griego en un selecto colegio, en la vieja casa de sus antepasados marinos, al otro lado de la bahía. Alberto, gracias a su tiempo libre, acepta dar clases particulares al hijo de un rico armador divorciado, un niño introvertido y difícil que vive encerrado en sí mismo. Sus primeros contactos con el niño fracasan, aunque pronto conoce a Carlota, su madre, una mujer fuerte e independiente. Entre ambos surge una gran atracción, convertida en una verdadera pasión amorosa.

Pese a los desajustes del guión -provocado por el aliento romántico de Werther y su aterrizaje en una realidad más prosaica- la película permanece como un digno intento de contar una historia a contracorriente y hacerlo sin traicio- 
nar su espiritu original. En ella se pone en evidencia el estilo personal de la realizadora y su elegante modo de hacer, algo que se consigue también con la música de Massenet y la delicada fotografía de Burmann, recreando un mundo gris y brumoso, en sintonía con el del romántico alemán.

Pilar Miró conoce bien la ópera de Massenet y la utiliza a fondo, eligiendo los fragmentos que siguen con fidelidad el desarrollo argumental. En cuanto a la fotografía, la creación de la atmósfera, básica para la realizadora, se convierte en uno de los soportes fundamentales para ese salto tan audaz que supone ir desde el sentimentalismo exaltado del XVIII hasta el prosaico siglo XX: coches, grúas, academias de danza, etc. Burmann, director de fotografía, une las brumas marinas y los cielos plomizos, que avanzan la humedad de los hayedos y la frialdad de los cementerios, con la crisis progresiva del protagonista, en una simbiosis de naturaleza y sentimientos prototípica del romanticismo. La crítica del momento destacó, sobre todo, la puesta en escena y su estilo: "una película elegante", se decía en la revista Positif; "una obra llena de delicadeza", precisaba Jean-Claude Seguin $(1994,119)$.

Werther es, por otro lado, para su directora una películaparéntesis entre dos nombramientos, pues apenas un mes después de su estreno, Miró fue nombrada Directora General de Radio Televisión Española, cargo que abandonaría dolorosamente en 1989. Esta amarga experiencia le serviría para concentrar sus fuerzas de nuevo en la realización cinematográfica. Barajó distintos proyectos y, entre ellos, trabajó intensamente en la novela de Patricia Highsmith, El temblor de la falsificación, finalmente sin llegar a materializarse, pues no pudo adquirir los derechos.

\section{BeLteNEBRos, UNA NOVELA DE PELÍCULA}

Pilar Miró se acerca a esta novela desde el encargo que le solicita Andrés Vicente Gómez, a través de la Compañia Iberoamericana, una producción con aspiraciones internacionales. Beltenebros, obra de Muñoz Molina publicada con gran éxito en 1989, se mueve en los territorios de la memoria, tratando de reconstruir la reciente historia de España con la mirada del que se siente deudor del cine negro y la novela policíaca. En ella se narra una acción de intriga y amor en el Madrid de la posguerra, con un enorme trasfondo político.
Se entiende el entusiasmo de Pilar Miró por la novela, ya que era una mujer comprometida políticamente. En verdad este trabajo le ofrecía una doble oportunidad: la de recuperar el mundo de la lucha clandestina contra el franquismo, reencontrando un estilo cinematográfico alimentado de paralelismos fílmicos de épocas anteriores -años 30 y $40-, y$, por otro lado, encontrar un argumento que le permitía realizar guiños de complicidad al espectador cinéfilo que podía reconocer las técnicas cinematográficas del cine negro americano (escenas oscuras, abundancia de planos medios, picados y contrapicados, diálogos mínimos, cine dentro de cine, etc.) (Vázquez, 2004).

Colaboró en el guión con Mario Camus y Juan Antonio Porto y contó con el beneplácito del novelista, quien también había visto adaptada al cine su novela anterior, El invierno en Lisboa. Al menos formalmente, Beltenebros es la tercera "adaptación" literaria de entre sus seis películas rodadas hasta la fecha; en realidad suponía un trabajo complicado, dado que la trama argumental era menos importante que los sentimientos que se agolpan en el alma de su protagonista. Darman, un exiliado político en Inglaterra tras la guerra civil, vuelve a Madrid en los años 60 con una misión secreta: descubrir quién es el topo infiltrado en la organización del Partido Comunista. Darman revivirá con esta misión otro viaje en plena guerra civil -cuando mató al traidor Walter- y volverá a recorrer senderos de la memoria ya transitados. La confusión de tiempos de las dos acciones paralelas que se cuentan también dificulta su traslación cinematográfica, aunque tras la voz en off autobiográfica del comienzo, se expresan todos los puntos de vista y las sensaciones de los protagonistas, como en la novela, y se respetan escrupulosamente las mismas alternancias temporales. Sin embargo, el guión extrañamente supo transmitir lo que el escritor había querido plasmar en su narración, siendo fiel al clima y a los personajes, aunque con ciertos cambios que, a la sazón, añaden nueva intriga a la trama y agudizan su carácter cinematográfico. Recuerda Pilar Miró que Muñoz Molina, al ver el copión de la película, después de la primera bobina, aseguró haberla reconocido como "su novela" e identificado inmediatamente las caras de los actores con sus personajes ${ }^{5}$.

Trabajo de encargo, guión basado en un argumento ajeno y escrito -como era habitual en la realizadora, en colaboración, Beltenebros es la menos autobiográfica de 
sus obras, la más cercana a lo que se podría denominar cine de género, una película en la que -como en Werther- destaca la sofisticación y elaboración de la puesta en escena, un ejercicio de estilo, al que también ayuda la fotografía expresionista y simbólica de Aguirresarobe. Después vendría El pájaro de la felicidad (1993), en una vuelta a la misma pulsión vital que motivó Gary Cooper que estás en los cielos. Ésta es la única película en la que Pilar Miró no interviene en el guión, al menos formalmente, en este caso escrito en solitario por Mario Camus, aunque al final logra personalizar el discurso del texto original.

\section{TU NOMBRE ENVENENA MIS SUEÑOS, LA VENGANZA, OTRA FORMA DE SOLEDAD}

En este caso la materia prima literaria no existía aún, como en el caso de Beltenebros; había, pues, que ir a su encuentro, también de manera sentimental. "En una conversación con Joaquín Leguina le retó a que escribiera la historia de una mujer consumida por el afán de venganza. Poco después Leguina le entregó Tu nombre envenena mis sueños"6. Pilar Miró tuvo en sus manos una narración que percibió tan claramente cinematográfica que, junto a Ricardo Franco -ayudado por Ángeles González-Sinde, no acreditada- comenzó a escribir el guión. Fue un trabajo más duro del previsto, según ambos admitieron después, porque se eliminaron algunos aspectos de la novela, en función del lenguaje cinematográfico (era excesivamente larga para la duración normal de un largometraje). Un guión excesivamente literario, demasiado respetuoso con la novela original, dijo la crítica?.

Según palabras de la directora se podía considerar una película "fundamentalmente de amor", aunque también hubiera venganza y pasión. Pertenece al género del thriller $y$, aunque transcurre durante la guerra y posguerra, en realidad no trata de la guerra civil española.

Leguina titula su novela siguiendo un verso de un poema terrible que, desde el exilio, escribió Luis Cernuda pensando en España ${ }^{8}$. Un poema que emociona a Leguina y también a Pilar Miró, y que sirve para hacer -en medio de tiempos de derrota- una reivindicación de la venganza de los perdedores en la España franquista.
Novela de Leguina, película de Miró, y guión de Ricardo Franco, todos se embarcaron en un homenaje a aquellos que perdieron la guerra, una historia sobre nuestro tiempo más oscuro. Un mundo tenebroso que ya había obsesionado a Miró en Beltenebros: en aquel Madrid de los victoriosos vivian derrotados que no se conformaban, por ello el argumento se trenza en torno a la aparición de los cadáveres de tres hombres y a la investigación de los inspectores Barciela y Valduque. Aparentemente uno de los hombres mató a los otros dos y luego se suicidó. Pero Ángel Barciela no cree en esa tesis y sigue investigando. Estos hombres durante la guerra de 1936 habian formado parte de la llamada quinta columna del ejército de Franco, y en Madrid, ciudad republicana, salian de noche a cometer asesinatos indiscriminados. Se hallaban ocultos durante el día en casa de la familia Buendía, cuya hija, Julia, los despreciaba. Ésta es la novia de Jaime, dirigente socialista que un día, durante la guerra, apareció muerto. Ángel Barciela centra sus investigaciones en esta familia, se enamora de Julia y es ella quien le va contando todo lo ocurrido. Hay grupos incontrolados que pretenden acabar con los que mataron a los tres hombres. Barciela, al final de sus investigaciones, hace que Julia salga de España, sabiendo que no volverá a verla.

Carmelo Gómez y Emma Suárez dan vida en la pantalla a Barciela y Julia. En ella Pilar Miró se encuentra con un personaje femenino que se inscribe a la perfección en esa galería de mujeres fuertes, capaces de combinar frialdad y ternura, marcadas por desencuentros amorosos, fieramente independientes, que tanto han caracterizado sus películas.

En realidad, Pilar Miró dio vueltas a la historia y escribió y reescribió muchos guiones con la única finalidad de contar, de una manera férrea, la historia de unos personajes que vivieron la guerra civil española, en una deuda pendiente con su generación (ésa que había vivido sus consecuencias, pero nunca se atrevió a preguntar, pues sabía que el silencio era la respuesta) ${ }^{9}$.

\section{La deuda teatral en el CINE de Miró: EL PERRO DEL HORTELANO}

Pilar Miró siempre demostró durante su trayectoria una destacada atención al teatro, cuyos primeros resultados se

ARBOR CLXXXVI 741 enero-febrero [2010] 79-88 ISSN: 0210-1963 
remontan a los ya citados como realizadora de televisión. De hecho, desde mediados de los sesenta y la década de los setenta, fue responsable de la adaptación a este medio de importantes dramaturgos extranjeros y españoles.

Desde el principio destaca su especial interés por dar a conocer a los clásicos, llevando a la pequeña pantalla adaptaciones como Los empeños de una casa, de Sor Juana Inés de la Cruz (1972), Las paredes oyen, de Juan Ruiz de Alarcón (1973) y Los tres maridos burlados, de Tirso de Molina (1975). De 1969 data su primera experiencia teatral en vivo, Sigfrido en Stalingrado, de Luigi Candoni. También se acercaría al mundo de la ópera con la Carmen de Bizet (1982), para luego acometer los montajes de Hijos de un dios menor (1982) y La verdad sospechosa.

Este último trabajo llega en 1991, tras el rodaje de Beltenebros: Pilar Miró aceptó la invitación del entonces director de la Compañía Nacional de Teatro Clásico, Rafael Pérez Sierra, para que ella eligiese una obra para su puesta en escena. Optó por La verdad sospechosa, de Ruiz de Alarcón, un clásico conocido de los tiempos de televisión. El texto fue adaptado por el poeta Claudio Rodríguez, actualizando sólo algunas estructuras del verso, demasiado arcaicas. Pilar Miró llevó a cabo un ejercicio de "actualización escénica".

Luego vendrian otros montajes en vivo: Las amistades peligrosas, adaptación de la obra de Choderlos de Laclos (1993), El cazador furtivo (1994) y Cristales rotos, de Arthur Miller (1995). Un año después le llegó el éxito del teatro en la gran pantalla, tras una ejemplar adaptación de El perro del hortelano. Con ella conquistó al público y a la crítica, lo que se tradujo en un millón de espectadores en taquilla, siete Goyas y un primer premio en el festival de Mar de Plata.

Ciertamente Pilar Miró siempre tuvo en alta consideración el acervo literario que nuestros clásicos nos habian dejado, un legado que también consideraba infravalorado. Pero su posición frente a ellos no era reverencial y manifestaba que había que perderles el respeto, para llegar a tratarlos como eran, "sin adornos"10; así lo había hecho ya en el montaje de La verdad sospechosa, adaptación que le sirvió como escuela de aprendizaje para Ilevar El perro del hortelano, y a Lope de Vega, a la gran pantalla.
El interés de Pilar Miró por el teatro clásico partió, en primer lugar, de su enorme potencial cinematográfico implícito; un potencial que supo explotar aprovechando las posibilidades que se derivaban de la estructura de las obras clásicas elegidas y gracias a la eficaz comicidad que en ellas se planteaba. En el caso de El perro del hortelano, señala María del Mar Mañas $(2003,141)$, que el tema de la obra le interesaba especialmente por la modernidad que suponía el que su protagonista, la condesa de Belflor, se enamorara de su secretario, que fuera esa misma mujer la que llevara las riendas de la relación y no apareciera como objeto o víctima del amor, además de ejercer el poder en solitario, sin necesidad de varones.

La magia de El perro del hortelano consistió en ir superando todos los obstáculos que impedian trasladar esta obra al cine: Pilar Miró deseaba conservar prácticamente todo de la obra original, en un trabajo más de traducción cinematográfica que de adaptación, y esa tarea iba a consistir en modernizar el léxico original del siglo XVII, aligerando el argumento en beneficio de la acción. Ella misma declaró que hacer una película en verso era "el mayor reto de su carrera", en un viaje hacia el Siglo de Oro que siempre le había atraído". "Es un proyecto arriesgado", aseguraba, "porque en España hay mucha prevención contra todo lo que no se suele hacer o no se ha demostrado que funciona. Sin embargo, puedo decir que Cyrano de Bergerac ha recaudado aquí 600 millones de pesetas y Mucho ruido y pocas nueces, 300" (El Mundo, 3 de junio de 1995).

Para su trabajo partió una vez más de una versión de Rafael Pérez Sierra, por aquel entonces Director de la Compañía Nacional de Teatro Clásico. La obra tuvo un año de preproducción y, antes de rodar, se dedicó casi dos meses a ensayos para que los actores se aprendieran la obra y practicaran su dicción. Fueron dirigidos por Alicia Hermida, experta en verso, quien además tuvo la misión de unificar el estilo del recitado de los distintos actores y actrices.

En realidad, cuando Pilar Miró decide acometer esta adaptación sigue una tradición que viene de los mismos comienzos del género cinematográfico, en el que ambas artes estaban unidas fuertemente. Como apunta Moncho Aguirre, "desde sus inicios, el cine español ha requerido de la materia argumental que proporcionan los textos teatrales, aun cuando nada haya más anticinematográfico que la 
pieza escénica, situada en el polo opuesto a los principios básicos que trajo el cine con su técnica antinaturalista" (Aguirre, 1999, 225). En la década de los 90 el cine español sigue inspirándose en el teatro y son una muestra de este interés por nuestros clásicos tanto la adaptación de Miró como la realizada por Gerardo Vera, a partir de la tragicomedia de Fernando de Rojas, La Celestina (Alonso, 2001, 375-393).

La adaptación de Pilar Miró es, pues, un tributo a la modernidad de nuestros clásicos; también, a veces, un enlace mágico con recursos típicamente teatrales, rememorados de forma manifiesta en muchas secuencias, por ejemplo, en el mantenimiento de los monólogos y de los apartes, concebidos en planos cortos y mirando hacia la cámara, en la comicidad física y gestual de los personajes, creando auténticos gags visuales, etc. Por otra parte, su versión recurre a técnicas cinematográficas que propician en algún momento el enriquecimiento del texto literario y del espectáculo teatral: cambios de espacio y tiempo, "aireando" las escenas sin respetar las unidades clásicas, para evitar la monotonía y el estatismo de la escena teatral, voz en off para reproducir los pensamientos de los personajes, 0 el enriquecimiento de la escenografía a través de la espectacularidad de las localizaciones, la decoración maravillosa de los espacios, la significativa luz de Aguirresarobe y el colorista y simbólico vestuario de Pedro Moreno, sin olvidar la eficacia de la música. Por lo demás, el conjunto aporta una perspectiva personal y diferente de la directora, siempre prevaleciendo su propia estética.

Poco antes de su muerte estrenó su segundo montaje de un clásico español: El anzuelo de Fenisa, de Lope de Vega (1996), en la apertura de una nueva etapa de la Compañía Nacional de Teatro Clásico, también por encargo de Pérez Sierra y con Magüi Mira en el papel de la ambiciosa cortesana de Palermo.

Vicente Molina Foix (1998, 39-41) nos cuenta sus últimos proyectos teatrales: la adaptación teatral de la película de Mankiewicz, La Huella, también quería completar una trilogía cinematográfica sobre el teatro clásico, con El castigo sin venganza, de Lope, debido al éxito de El perro del hortelano, para luego cerrar con un drama tan rotundo como La señorita Julia, de Strindberg, que completaría una sugerente galería de retratos femeninos.

Estos trabajos quedaron truncados tras su muerte y estaban, como vemos, claramente marcados por el signo teatral, en una continuidad que reflejaba hasta qué punto Pilar Miró se había dejado fascinar por la magia de ese "espectáculo total". Pero al final no logró cumplir con sus expectativas, iguales a las de Andrea, en Gary Cooper que estás en los cielos; así lo dice: "John Ford dirigió 70 películas, Howard Hawks, 58, Hitchcock, 50. Yo no quiero ser menos. Ésos son mis planes de futuro".

\section{NOTAS}

1 Toda la literatura realista fue objeto de atención de la realizadora. En especial sentía predilección por la obra narrativa de Emilia Pardo Bazán, y prueba de ello es que más tarde intentaría, aunque en vano, la adaptación de Los pazos de Ulloa (González, 2006)

2 España todavía tiene deudas pendientes con un pasado sin resolver y eso afecta muchísimo a los creadores. Las cosas cambian poco a poco con la Transición. En 1976 se suprime el NO-DO. En el año de las primeras elecciones democráticas, 1977, se acaba con la censura previa. También se legaliza Viridiana (Luis Buñuel, 1961) y se autoriza El acorazado Potemkin (Bronenosets Potemkin, Sergei M. Eisenstein, 1925). A pesar de todo sigue habiendo todavía bastantes limitaciones a la libertad de expresión y la propia Pilar Miró sufrirá sus consecuencias con El crimen de Cuenca (1979).

Aceptado: 9 de febrero de 2009 
3 T. García de la Puerta, "La petición: audaz e interesante", Pueblo, 7/10/1976; C. Rico-Godoy, "Una buena Miró", Cambio 16, 254, 18-24 de octubre, 1976, 104; F. Lara, "El debut cinematográfico de Pilar Miró", Triunfo, 717, 23/10/1976, 65-66; J. Fernández Santos, "Los amores prohibidos", El País, 10/10/1976.

4 Pocos días después se produciría una gran manifestación en la Plaza de Oriente y en el Valle de los Caídos convocada por nostálgicos del franquismo que conmemoraban el quinto aniversario de la muerte de su caudiIlo. Se temían en el estreno de Gary Cooper altercados parecidos a los de La prima Angélica, de Saura, o en Camada negra, de Manuel Gutiérrez Aragón. Seguía la tensión social del país y 1981 comenzó bajo un clima de miedo e incertidumbre (Galán, 2006, 154-160).

5 A. Muñoz Molina, "La cara de Darman", Fotogramas, 1.780, diciembre 1991, 97.

6 Tomás Garcia Yebra, "La fuerza de Pilar Miró se apagó", El Diario Vasco, 20/10/1997.

7 M. Alcalá, "Tu nombre envenena mis sueños: demasiada literatura", Reseña, 277, noviembre 1996, 16-17; LI. Bonet, "El filme de Pilar Miró llega lastrado por un exceso de pasión y literatura", La Vanguardia, 23/09/1996; A.

8 Castro, "Tu nombre envenena mis sueños: el título, lo mejor con diferencia", Dirigido por..., 250, octubre, 1996, 8.

9 D. Muñoz, "Ojalá mi película sirva para que no se olviden las consecuencias de la guerra civil", La Vanguardia, 23/09/1996 (en entrevista a la directora).

10 La crítica fue unánime en el elogio a la adaptación del clásico que había hecho Miró, destacando sólo una voz discordante frente al triunfalismo general, la crítica de José Enrique Monterde, "Una adaptación inadecuada", Dirigido por..., 252, diciembre, 1996, que señalaba la falta de relieve de la puesta en escena, más adecuada a las funciones didáctico-recreativas de la televisión.

11 Cristina Gil, "Hacer una película en verso es el mayor reto de mi carrera", Ya, 26/11/1996 (en entrevista a la directora).

\section{BIBLIOGRAFÍA}

Alonso Veloso, M. ${ }^{a}$ José (2001): "El perro del hortelano, de Pilar Miró: una adaptación no tan fiel de la comedia de Lope de Vega", Signa, 10, 375-393.

Angulo, Jesús (1998): "El cine de Pilar Miró", Nosferatu, 28, 18-32.

Galán, Diego (2006): Pilar Miró. Nadie me enseñó a vivir, Barcelona, Plaza-Janés.

Gimferrer, Pere (1999): Cine y literatura, Barcelona, Seix-Barral.

González Herrán, José Manuel (2006): "Novelas españolas del siglo XIX en series de TV", Aula de Letras, 1, 66-68.

- (2007): "Pilar Miró adapta a la televisión un cuento de Emilia Pardo Bazán: de 'Por el arte' (1891) a 'Ópera en Marineda' (1974)", M. A. Millán y C. Peña (eds.): Las mujeres y los espacios fronterizos, Zaragoza, Prensas Universitarias de Zaragoza, 71-87.

Jaime, Antoine (2000): Literatura y cine en España (1975-1995), Madrid, Cátedra.

Mañas, M. a del Mar (2003): "Reflexiones sobre El perro del hortelano", Dicenda, 21, 139-156.

Massanés, Natividad (1978): Crecer en España. La familia vista a través de la infancia de seis mujeres destacadas, Barcelona, Argos Vergara.

Molina Foix, Vicente (1998): “¿Dónde acaba el teatro?", Nosferatu, 28, 39-41.
Moncho Aguirre, Juan de Mata (1999): Las adaptaciones teatrales en el cine español. Encuentros sobre literatura y cine, Zaragoza, Instituto de Estudios Turolenses, 225-252.

Monterde, José Enrique (1993): Veinte años de cine español (1973-1992): Un cine bajo la paradoja, Barcelona, Paidós.

Peña-Ardiz, Carmen (1996): Literatura y cine. Una aproximación comparativa, Madrid, Cátedra.

Pérez Millán, Juan Antonio (1992): Pilar Miro. Directora de cine, Valladolid, Semana Internacional de Cine de VaIladolid.

Sánchez Nogueira, José Luis (2000): De la literatura al cine, Barcelona, Paidós.

Santamarina, Antonio "Telenovelas, teleteatro y teleseries", en Nosferatu, 1998, 66-70.

Seguin, Jean-Claude (1994): Histoire $d u$ cinéma espagnol, París, Nathan.

Vázquez Naviera, Marta María (2004): "Beltenebros y la intertextualidad", $X$ Congreso de la Asociación Española de Semiótica, Logroño, Universidad de La Rioja-Asociación Española de Semiótica, 1.015-1.023.

\section{FILMOGRAFÍA}

Beltenebros (Dir. Pilar Miró, 1991).

El crimen de Cuenca (Dir. Pilar Miró, 1980).

Gary Cooper que estás en los cielos (Dir. Pilar Miró, 1980).

Hablamos esta noche (Dir. Pilar Miró, 1982).

El pájaro de la felicidad (Dir. Pilar Miró, 1993).

El perro del hortelano (Dir. Pilar Miró, 1996).

La Petición (Dir. Pilar Miró, 1976).

Tu nombre envenena mis sueños (Dir. Pilar Miró, 1996).

Werther (Dir. Pilar Miró, 1986). 